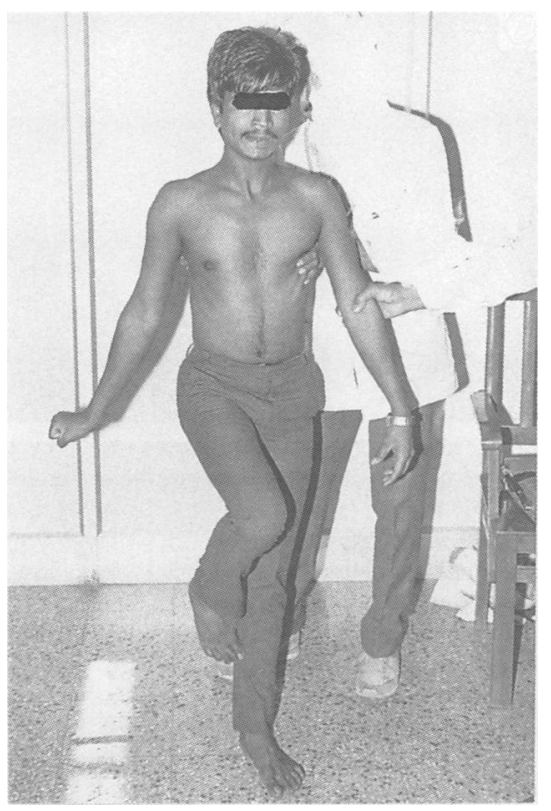

Figure 1 An attack of right hemidystonia induced by treadmill exercising.

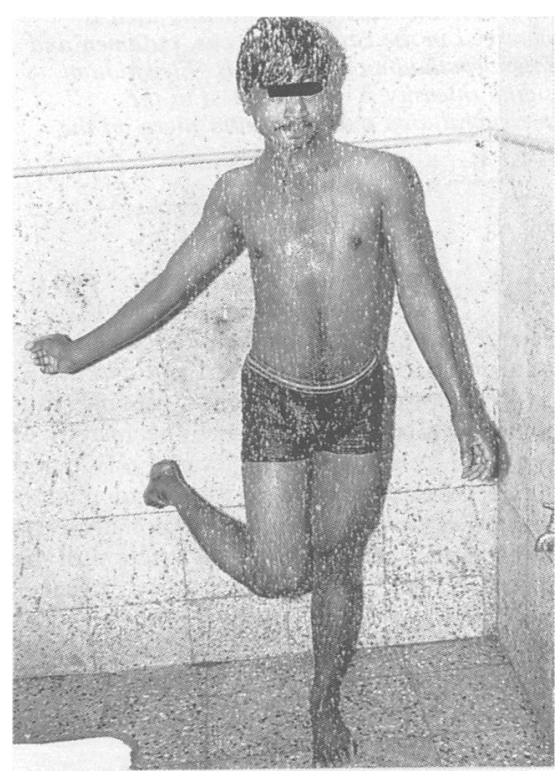

Figure 2 An attack induced by cold water shower.

Haemogram, liver function tests, serum, calcium, phosphorus, copper, caeruloplasmin estimations were normal. Blood sugar levels in the fasting state and during the ictus were normal. Slit lamp examination for K-F ring was negative. Radiological evaluation with CT scan of the head, radiographs of the chest and skull was normal. An interictal EEG whilst awake, showed frontally dominant intermittent rhythmic delta activity. No epileptiform discharges were seen.

Serial trials of phenobarbitone $(120 \mathrm{mg} /$ day), phenytoin sodium ( $300 \mathrm{mg} /$ day) and clonazepam ( $2 \mathrm{mg} /$ day) for four weeks each did not help. A year later the attacks were unchanged.

Paroxysmal choreoathetosis emerged as a clinical entity in a description of a family by Mount and Reback in $1940 .^{2}$ Clinical features of the three subgroups are summarised in the table. Our case belongs to the inter-

Table Familial paroxysmal choreoathetosis

\begin{tabular}{|c|c|c|c|}
\hline & $\begin{array}{l}\text { Paroxysmal dystonic } \\
\text { choreoathetosis }\end{array}$ & $\begin{array}{l}\text { Paroxysmal kinesigenic } \\
\text { choreoathetosis }\end{array}$ & Intermediate type \\
\hline Inheritance & $\begin{array}{l}\text { Autosomal dominant } \\
\text { Single sporadic Case }\end{array}$ & $\begin{array}{l}\text { Autosomal dominant } \\
\text { Sporadic } \\
\text { ? Recessive }\end{array}$ & Autosomal dominant \\
\hline $\begin{array}{l}\text { Age of onset } \\
\text { Frequency of attacks } \\
\text { Duration of attacks }\end{array}$ & $\begin{array}{l}\text { Neonatal/infancy } \\
1-2 / \text { month to } 3 / \text { day } \\
2 \text { min to } 6 \text { hours }\end{array}$ & $\begin{array}{l}\text { Infancy to } 4 \text { th decade } \\
1 / \text { month to } 100 / \text { day } \\
\text { Usually } 1 \text { minute; } \\
\text { always less than } 5 \\
\text { minutes }\end{array}$ & $\begin{array}{l}2 / \text { month; rarely daily } \\
5 \text { to } 30 \text { minutes }\end{array}$ \\
\hline Induced by & $\begin{array}{l}\text { Alcohol, other drinks, } \\
\text { fatigue, rest after } \\
\text { physical stress, } \\
\text { excitement }\end{array}$ & $\begin{array}{l}\text { Sudden movements, } \\
\text { startle }\end{array}$ & $\begin{array}{l}\text { Continous exertion, passive } \\
\text { movements, local vibration }\end{array}$ \\
\hline Therapy & Clonazepam & $\begin{array}{l}\text { Phenytoin } \\
\text { Phenobarbitone }\end{array}$ & Clonazepam? \\
\hline
\end{tabular}

Modified from Buruma and Roos

mediate type and is the first sporadic case in this group. The history, examination and investigations ruled our underlying conditions, such as, cerebral palsy, multiple sclerosis, Wilson's disease, idiopathic hypoparathyroidism, hypoglycaemia, encephalitis or space occupying lesion which could produce focal dyskinesias.

The well documented families of Lance ${ }^{4}$ and Plant $e t a l l^{5}$ which form the basis of the intermediate type, are characterised by cases whose attacks were induced by prolonged exercise. In our case the attacks were not only induced by prolonged exercise, such as, running, but also by prolonged work with a part of the ipsilateral limb. A similar observation is made in case 1 by Plant $e t a^{5}$ in which writing to dictation could induce the attacks of involuntary movements.

As a trigger factor cold temperature has not been reported in the intermediate type. Absence of response to warm water shower indicates that the trigger factor is cold related and not related to the striking force of the water drops to the body surface. Cold breeze also induced the attacks. This is the first case of the intermediate type to show unilaterality the involuntary movements. In the cases of Lance $^{4}$ and Plant et $a l^{5}$ the involuntary movements predominantly affected both the lower limbs and only when severe, involved the whole body. The EEG finding of frontally dominant intermittent rhythmic delta activity in the awake state is another new observation although possibly of non-specific signifi- cance. Previously reported cases had normal EEGs.

The trigger factors and involuntary movements in our case, suggest a functional disturbance of the contralateral basal ganglia or their connections leading to abnormal responsiveness to external stimuli sensed by kinaesthetic and cold receptors.

fawaharlal Nehru Medical College and KLE Society's Hospital, and Medical Research Centre, Belgaum, India

I am grateful to the Principal, Jawaharlal Nehru Medical College and the Administrator of the KLE Society's Hospital and Medical Research Centre for granting permission to publish this report.

1 Buruma OJS, Roos RAC. Paroxysmal choreoathetosis. In: Vinken PJ, Bruyn GM, Klawans $\mathrm{HL}$ eds. Handbook of clinical neurology Vol 5(49). Amsterdam: Elsevier 1986, 349-58.

2 Mount LA, Reback S. Familial paroxysmal choreoathetosis. Preliminary report on a hitherto undescribed clinical syndrome. Arch erto undescribed clinic

3 Kertesz A. Paroxysmal kinesigenic choreoathetosis. An entity within the paroxysmal choreoathetosis, description of 10 cases including eoathetosis, description of 10 cases including 1 autopsied. Neurology 1967;17:680-90.

4 Lance JW. Familial paroxysmal dystonic choreoathetosis and its differentiation from related syndromes. Ann Neurol 1977;2:285-93.

5 Plant GT, Williams AC, Earl CJ, Marsden CD Familial paroxysmal dystonia induced by exercise. I Neurol Neurosurg Psychiatry 1983;46:345-8.

\section{An intracerebral abscess following an aneurysm clipping}

A sixty one year old right handed woman was admitted as an emergency having sustained a subarachnoid haemorrhage resulting in coma. A CT showed subarachnoid blood in the basal cisterns and a Sylvian fissure. Cerebral pan-angiography showed a bilocular anterior communicating artery aneurysm. On day 17 after the bleed, a right pterional craniotomy was performed and the anterior communicating artery aneurysm was clipped. Her recovery was uneventful except for a urinary tract infection. She was discharged on day 13 after the operation.

Four weeks after the operation she was again admitted with a history of seven days of right frontal headache. There was no neurological deficit and no papilloedema. CT (figure a) suggested a right frontal infarct. A lumbar puncture was normal.
She improved with simple analgesics and was allowed home after four days. Six weeks later she again presented with a two week history of progressive generalised headaches, vomiting and a left sided weakness. Examination revealed a left sided weakness, the presence of primitive frontal reflexes but no papilloedema. She was pyrexial (temperature $37 \cdot 5^{\circ} \mathrm{C}$ ). Further CT (figure b) showed a cystic enhancing mass in the right frontal area. A right frontal burr-hole was made and the mass aspirated, $40 \mathrm{mls}$ of pus was obtained. Bacteriological studies showed Gram positive cocci and a growth of Staphylococcus aureus.

She was initially treated with gentamycin, metronidazole and benzyl penicillin. This was later changed to lincomycin, sodium fusidate and metronidazole. Antibiotics were continued for ten weeks-one week intravenously, nine weeks orally. Her symptoms improved as did the left hemiparesis; the 


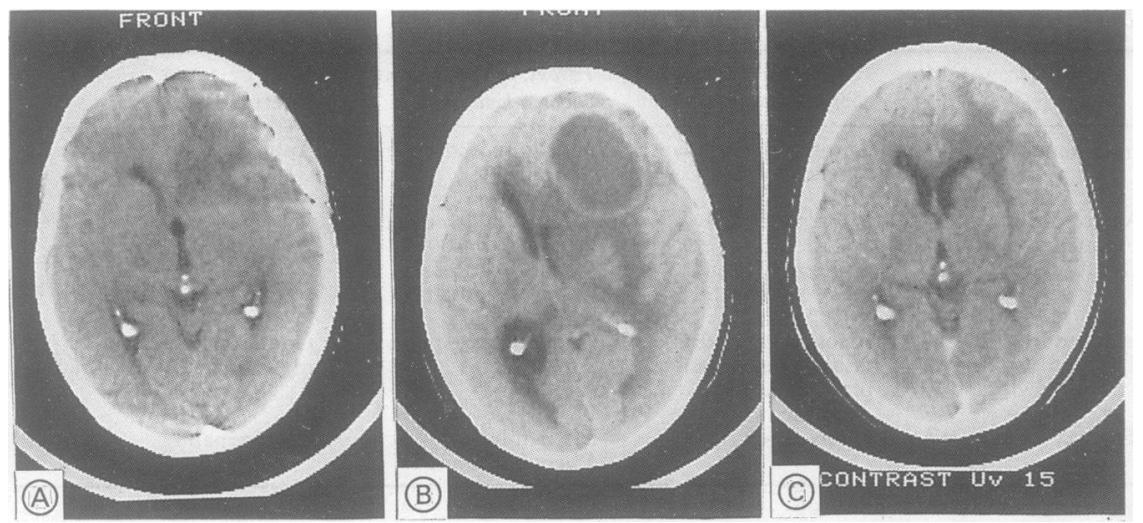

Figure A) CT without contrast showing low density area in the right frontal region; B) $C T$ without contrast showing cystic mass in the right frontal area which is enhanced; C) $C T$ scan at three months after aspiration showing low density area. There is no abscess and no shift.

primitive frontal reflexes slowly disappeared and she remained apyrexial. CT scans at weekly intervals showed no re-accumulation (figure $c$ ) and she regained her normal state of health.

The risk of infection after craniotomy is between $1-3 \%$ but after surgery from aneurysm, is less than $1 \%$. Cerebral abscesses are common secondary to otorhino-laryngo-logical infection. ${ }^{1}$ In this case craniotomy did not pass through an infected sinus. Among other causes are haematogenous spread in patients with cyanotic congenital heart disease and following oesophageal dilatation. ${ }^{23}$ In our case, the infection was most likely introduced at the time of operation. The mortality from intra-cerebral abscess ranges between $10-70 \%$ in untreated patients. The surgical management options include: tube drainage, masupialisation, Kahn's migration method, tapping, aspiration and excision. At presen only two methods are used, aspiration and excision. ${ }^{4}$ Excision of the abscess cavity carries a high risk of mortality and morbidity.

\section{MRI in hemiballism due to Sydenham's chorea}

Parainfectious and immunologically mediated chorea may be caused by a cytotoxic reaction in the basal ganglia. ${ }^{2}$ We report the MRI appearances in a patient with hemiballism due to Sydenham's chorea.

A 17 year old woman showed right sided hemiballism of subacute onset. She had a history of hyperthyroidism and repeated tonsillitis, but no family history of neurological diseases. Routine laboratory investigations showed normal blood cell counts and blood chemistry. Positive immunological findings were c-reactive protein (CRP) 16.5 (normal; $<0.3$ ), anti-streptlysin-O (ASO) 181 (<155), anti-streptokinase (ASK) $2560(<640)$ and decreased IgA of $32.9 \mathrm{mg}$ dl (135-340). There were no abnormal findings in anti-virus titres, hormonal levels, CSF and ECG. Although her involuntary movements were reduced by administration of sodium valporate and phenytoin, phenytoin caused an allergic agranulocytosis which required treatment with prednisolone, $40 \mathrm{mg}$ daily for 14 days. Prednisolone alleviated both the drug allergy and involuntary movements. After withdrawal of prednisolone
An intracerebral abscess after clipping of an aneurysm is rare. Our case demonstrates that they can be managed by minimal surgery and antibiotics without the need to remove the clip.

F M KAPASI Department of Neurosurgery,
Walton Hospital, Liverpool

Correspondence to: Dr Kapasi, Ysbyty Glan Clwyd, Bodelwyddan, Rhyl, Clwyd.

1 Arseni C, Ciurea AV. Cerebral abscesses secondary to otorhinolaryngological infections. $1988 ; 49(1): 22-36$.

2 Chakraborty R, Bidwai PS, KakVK, et al. Brain abscess in cyanotic congenital heart disease. Indian Heart f 1989;41(3): 190-3.

3 Pencek TL, Burchiel KJ. Delayed brain abscess related to a retained foreign body with culture of Clostridium bifermentans. Case report. $\mathcal{F}$ Neurosurg 1986;64(5):813-5.

4 Surgical treatment of brain abscess. Neurosurgery 1988;22(4);724-30.

5 Maurice Williams RS. Experience with “Open evacuation of pus" in the treatment of intracerebral abscess. Br $\mathcal{f}$ Neurosurg 1987;1(3): 343-51. haloperidol $5 \mathrm{mg}$ IM followed by $2.25 \mathrm{mg}$ daily by mouth for 20 days and the hemiballism resolved during this time. CT scan showed left caudate nucleus swelling only, and angiography was normal. T2 weighted MRI 31 days after onset of symptoms demonstrated hyperintensities in the left caudate nucleus, putamen, lateral pallidum, perirubral area and substantia nigra (Figure). Hyperintensity in the prerubral area suggested involvement of the subthalamic nucleus or its connecting pathways. "Fourteen months later, she had a convulsion with mental confusion. No ballistic movements were observed and a repeat MRI was normal. There were bursts of theta and delta wave activity in the EEG. Serological test showed positive antinuclear antibody (ANA: X320, speckled type) and negative anti-DNA antibody.

Despite the fact that systemic chorea is associated with systemic disease, unilateral involuntary movement are often seen. ${ }^{2}$ The lesions in our case seemed to spread during neural connections rather than in a vascular territory. The lesions were oedematous but was unlike lesions seen in vascular accidents or multiple sclerosis plaques. An allergic A study of 386 cases. Zentralbl-Neurochir

hemiballism reappeared and was treated with
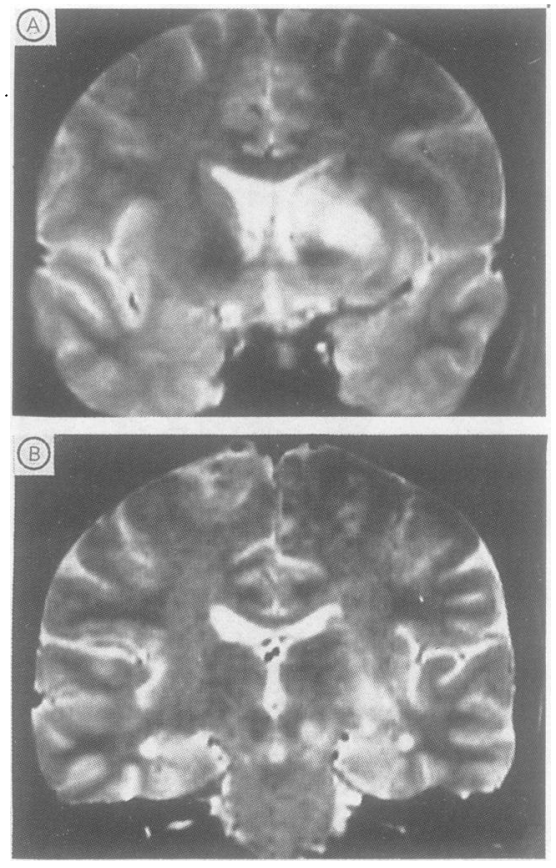

Figure T2 weighted MRI (TR 2000, TE 100). A: Elevated signal intensity area is observed in the caudate nucleus, putamen and lateral pallidum on the left. B: Elevation of signal intensity is also observed in the perirubral area and substantia nigra on the left.

reaction to phenytoin, amelioration of hemiballism by prednisolone and positive ANA, which appeared later, suggest an immunologically mediated disorder. The history of repeated tonsillitis and elevated ASO and CRP indicated the diagnosis of Sydenham's chorea. Sydenham's chorea is thought to be an immunologically mediated reaction in the basal ganglia and subthalamic nucleus. ${ }^{3}$ Increased signal intensity in T2 weighted MRI at an early stage suggests an exudative or inflammatory lesion, which is compatible with the hypothesis of an immunological reaction in the basal ganglia.

Besides lesions of the subthalamic nucleus, hemiballism can be caused by single or combined lesions of the striatum, pallidum, substantia nigra, thalamus and their connections in each other. ${ }^{45}$ Where the pallidum is affected, the lesion is usually in the outer segment. Disinhibition of the medial pallidum by the lesion of the inhibitory subthalamopallidal pathway and a subthalamic nucleus itself is thought to cause ballism.s MRI of our case showed a wide-spread lesion in the basal ganglia and related structures on the left. Of these, the perirubral area, where the subthalamopallidal pathway is located, and lateral pallidum were thought to be responsible for hemiballism.

Radiological findings of symptomatic chorea have been poorly documented. MRI of the present case offers the information about distribution and possible nature of the lesion.

$$
\begin{array}{r}
\text { MASAAKI KONAGAYA } \\
\text { Department of Neurology, } \\
\text { Suzuka National Hospital, Suzuka } \\
\text { YOKO KONAGAYA } \\
\text { Department of Neuroradiology, } \\
\text { Nagoya University School of Medicine, } \\
\text { Nagoya, fapan }
\end{array}
$$

Correspondence to: Dr Konagaya 